\title{
EUS-guided transmural drainage for peripancreatic fluid collections using fine needle and stiff fine guidewire without electrocautery: An optional safe technique
}

\author{
This article was published in the following Dove Press journal: \\ Therapeutics and Clinical Risk Management \\ 23 June 2009 \\ Number of times this article has been viewed
}

\section{Hiroyuki Miyatani \\ Yukio Yoshida}

Department of Gastroenterology, Jichi Medical University, Saitama Medical Center, Saitama, Japan
Correspondence: Hiroyuki Miyatani Department of Gastroenterology, Jichi Medical University, Saitama Medical Center, I-847 Amanuma, Omiya, Saitama, Saitama 330-8503, Japan

Tel +814864721 II

Fax +8I 486485 I88

Email miyatani@omiya.jichi.ac.jp
Abstract: Endoscopic transmural drainage by using endoscopic ultrasound (EUS) guidance is not always safe because of the risk of bleeding and perforation. Additionally, the effective area of the EUS-guided procedure using a large diameter needle is relatively narrow. We evaluated the effectiveness and safety of EUS-guided drainage using fine needle and stiff fine guidewire without electrocautery. From November 2006 to July 2008, EUS-guided transmural drainage was performed in six consecutive patients for peripancreatic fluid collections. Puncture via EUS was performed by using a 22-gauge needle. A 0.018-inch guidewire was advanced through the needle and into the peripancreatic fluid collections. After the puncture site was dilated, a $6 \mathrm{Fr}$ tube was immersed in the peripancreatic fluid collections. Five of six patients were successfully drained and treated effectively. One patient was unable to be drained because the dilator could not penetrate the gastric wall. The 22-gauge fine needle and stiff fine guidewire technique can be an alternative to the standard method for difficult puncture sites and risky cases.

Keywords: EUS-guided drainage, peripancreatic fluid collections, fine needle, stiff fine guidewire

\section{Introduction}

Endoscopic transmural drainage by using endoscopic ultrasound (EUS) guidance is minimally invasive and has become the established method for management of peripancreatic fluid collections (PFC). Although the safety and efficacy of PFC have been reported, severe complications, for example, hemorrhage and perforation, could occur during the procedure, especially with electrocautery. The standard method using 19-gauge needle and 0.035 -inch guidewire has been reported without electrocautery. However, it is difficult to puncture the lesion when located at certain places where is necessary to flex the tip of the endoscope excessively. 22-gauge needle is able to puncture more extensive sites in the gastrointestinal wall than 19-guage needle, including the descending part of the duodenum. We herein report the easiness and safety of the modified EUS-guided drainage method using 22-gauge needle and stiff fine guidewire.

\section{Materials and methods}

From November 2006 to July 2008, EUS-guided transmural drainage was performed in six consecutive patients for PFC (four men, two women: mean age 
$55 \pm 16$ years). All patients had failed or were difficult for transpapillary pancreatic drainage. Before drainage, all patients underwent contrast-enhanced computed tomography $(\mathrm{CT})$. The procedures were performed on inpatients. The indication criteria of drainage by $\mathrm{CT}$ are as follow: PFC was located $<10 \mathrm{~mm}$ from intestinal wall, and no intervening vessels were located between PFC and the intestinal wall.

EUS-guided drainage was performed by a single endoscopist (HM). All patients were sedated by intravenous administration of flunitrazepam and buprenorphine. EUS was performed with a linear echoendoscope (GF-UCT 2000; Olympus Optical, Tokyo, Japan). After identification of the lesion, puncture via EUS was performed by using a 22-gauge needle. The contents of the PFC were confirmed by aspiration and the location of the needle tip was shown by contrast injection under fluoroscopy. After the needle was flushed by saline, a 0.018-inch Pathfinder guidewire (Microvasive endoscopy; Boston Scientific Corp., Natick, MA, USA) was advanced through the needle and into the PFC. The needle was removed and a tapered-tip endoscopic retrograde cholangiopancreatography (ERCP) catheter (PR-110Q; Olympus) was advanced into the $\mathrm{PFC}$ over the guidewire. The tapered-tip catheter was then exchanged with a 7 Fr. Soehendra dilator (Cook Endoscopy, Winston-Salem, NC, USA), and a 6 Fr pigtail endoscopic nasobiliary drainage (ENBD) catheter (Cook Endoscopy) was immersed in the PFC. These procedures were performed under fluoroscopy. Cyst lavage was performed though the ENBD catheter by infusion of $20 \mathrm{ml}$ saline and $60 \mathrm{mg}$ gentamicin. Two weeks after drainage, effectiveness of the treatment was evaluated by CT scan. If the treatment was ineffective, drainage was continued. If continuous drainage was necessary for the patient, internal drainage by $7 \mathrm{Fr}$. tube stent immersion was performed or two weeks nasocystic drainage was added to the regimen.
An antimicrobial agent was administered until C-reactive protein was almost negative.

Endoscopic findings were documented in detail: site of PFC, site from where the PFC was accessed, EUS characteristics of PFC, and any procedure-related complications.

\section{Results}

A total of six patients were enrolled this study. Five patients were successfully drained without complication. One patient failed during the dilation procedure because the ERCP catheter and dilator could not penetrate the gastric wall. The patient was repunctured by a 19-guage needle and was then successfully drained.

Three patients had intractable infected pancreatic cyst (Patient 2 and 3) or peripancreatic abscess (Patient 5) after acute pancreatitis (Table 1). Methicillin-resistant Staphylococcus aureus was cultured in two of these three patients (Patient 2 and 3). One patient had pancreatic pain caused by enlarged pancreatic cyst with chronic pancreatitis. One patient was post-pancreaticoduodenectomy with peripancreatic abscess. All patients had the PFC procedure performed successfully. The sizes of PFC were 50 187 mm (average, $94.7 \pm 49.1 \mathrm{~mm}$ ). Endoscopically visible luminal compression was shown in two cases. Time for procedure was 27 58 minutes (average, $41.0 \pm 13.3$ minutes). Patient 5 was punctured through the afferent limb of the jejunal loop because of residual stomach. Two of five patients had only nasocystic drainage performed (Patient 1 and 5). Two of five patients had an internal drainage stent exchanged (Patient 2 and 4). Two of five patients required cyst lavage for two weeks (Patient 2 and 3). Symptoms disappeared and laboratory data improved in all cases treated by this method. Additional procedures such as insertion of bigger or multiple stents, or endoscopic necrosectomy were not required. Finally, five cases with drainage performed by this technique were treated successfully. No $\mathrm{PFC}$ was recurred during follow-up (average 52 months).

Table I Cases of EUS-guided transmural drainage

\begin{tabular}{lllllll}
\hline Patient & Age & Sex & Disease and etiology & $\begin{array}{l}\text { Size of cyst } \\
(\mathbf{m m})\end{array}$ & $\begin{array}{l}\text { Procedure } \\
\text { time }(\mathbf{m i n})\end{array}$ & $\begin{array}{l}\text { Puncture site } \\
\text { luminal compression }(+/-)\end{array}$ \\
\hline I & 33 & M & Chronic pancreatitis & 50 & 58 & Post-upper body, stomach (-) \\
2 & 69 & F & Acute necrotizing pancreatitis & 100 & 27 & Post-upper body, stomach (-) \\
3 & 74 & F & Acute necrotizing pancreatitis & 187 & 46 & Post-inferior body, stomach (+) \\
4 & 40 & M & Acute necrotizing pancreatitis & 95 & 46 & Second portion, duodenum (+) \\
5 & 59 & M & Abscess post-PD & 75 & 28 & Afferent loop (-) \\
6 & 57 & M & Acute necrotizing pancreatitis & 61 & Failure & Anterior angle $(-)$ \\
\hline
\end{tabular}

Abbreviations: EUS, endoscopic ultrasound; PD, pancreatoduodenectomy. 


\section{Discussion}

EUS-drainage by using a needle knife with electrocautery and 19-gauge needle without electrocautery has been reported in many cases. ${ }^{1-10}$ These methods have become standard; however, some problems concerning the complications and ease of the procedure remain. The merit of the method by using needle knife with electrocautery is in its ease in penetrating the intestinal wall, particularly the gastric wall which is thick and difficult to penetrate with a thick needle. Additionally, the remaining procedures (dilation, tube insertion, and so on) are easy to perform because the hole produced after penetration with electrocautery is relatively large in size. However, massive hemorrhage by injuring the intestinal wall vessels has been reported in some cases. ${ }^{8,11,12}$ In cases of welldeveloped collateral vessels with portal hypertension by portal obstruction, greater consideration should be given to hemorrhage. ${ }^{11}$ Perforation also has been reported by using needle knife. ${ }^{11,13-15}$ The reduced visibility of a needle knife than the standard fine-needle aspiration (FNA) needle may be one reason for perforation and hemorrhage. ${ }^{11,16}$ In case of insufficient adhesion between intestinal wall and pancreatic cyst, air insufflations may dissociate the cyst from the intestinal wall. We encountered a case of pancreatic pseudocyst in the pancreatic head which was punctured by needle knife with electrocautery. The guidewire was dislocated from the pancreatic cyst when the tip of the echoendoscope was moving in order to view the front of the puncture site.

On the other hand, EUS-drainage by 19-gauge is safer than drainage by needle knife in terms of bleeding and perforation. ${ }^{9}$ However, it is difficult to puncture specific areas of gastroduodenal wall such as the descending portion of the duodenum with this needle because of the hardness of the needle. The 19-guage needle requires stronger force to penetrate the gastrointestinal wall than with a thinner needle. The endoscope tip often moves away from the gastrointestinal wall at the time of puncture. This procedure is possible for only experts in EUS-guided puncture under various circumstances and in various parts of gastroduodenal wall.

It is easy to puncture a wider area of the gastroduodenal wall by using a 22-gauge needle. In our study, it seemed difficult to perform EUS-guided drainage in two cases (Patient 4 and 5) by the standard method. We could easily puncture the second part of the duodenum and the afferent loop in practice with the 22-guage needle. Both areas are difficult to puncture with a 19-gauge needle. Additionally, it is easy to control the direction and the puncture depth of the thinner needle because of easy penetration. The merit of using a thinner needle is associated with the safety and the possibility of puncture under various circumstances such as a small or narrow lesion on the ultrasound image requiring correct puncture angles. The demerit of this method is difficulty in penetrating the gastric wall with a dilator because of the thinness of the puncture site. A 6 or 7 Fr. dilator was not often able to penetrate the gastric wall before penetration with a PR-110Q ERCP catheter, although it is easy to penetrate the duodenal wall because of the wall thinness. If a dedicated dilator for this method is developed, the procedure must be easier and the indications extended. Once the dilator penetrates into the cyst through the intestinal wall, not only a nasocystic catheter, but also an internal drainage stent with nasocystic catheter is easily placed by dilating the puncture site using a balloon dilator. ${ }^{9}$

\section{Conclusions}

EUS-guided transmural drainage without electrocautery using fine needle and stiff fine guidewire was safe, easy, and applicable under various situations. Almost all cases of PFC are able to be treated by the standard method. However, the fine needle and stiff fine guidewire method is an alternative technique for difficult puncture sites and risky cases and will become easier and safer when a new dilator is developed.

\section{Disclosure}

Hiroyuki Miyatani is responsible for the conception and design, data collection, analysis, and drafting of this article. Yukio Yoshida had final approval of the paper to be published. The authors report no conflicts of interest in this work.

\section{References}

1. Grimm H, Binmoeller KF, Soehendra N. Endosonography-guided drainage of a pancreatic pseudocyst. Gastrointest Endosc. 1992;38(2) $170-171$.

2. Wiersema MJ. Endosonography-guided cystoduodenostomy with a therapeutic ultrasound endoscope. Gastrointest Endosc. 1996;44(5) 614-617.

3. Gerolami R, Giovannini M, Laugier R. Endoscopic drainage of pancreatic pseudocysts guided by endosonography. Endoscopy. 1997;29(2):106-108.

4. Ardengh JC, Della Libera E, Ferrari AP. Endosonography-guided drainage of pancreatic pseudocyst without gastric or duodenal compression. Endoscopy. 1998;30(6):S71-S72.

5. Giovannini M, Bernardini D, Seitz JF. Cystogastrotomy entirely performed under endosonography guidance for pancreatic pseudocyst: results in six patients. Gastrointest Endosc. 1998;48(2):200-203.

6. Vilmann P, Hancke S, Pless T, Schell-Hincke JD, Henriksen FW. One-step endosonography-guided drainage of a pancreatic pseudocyst: a new technique of stent delivery through the echo endoscope. Endoscopy. 1998;30(8):730-733.

7. Giovannini M, Pesenti C, Rolland AL, Moutardier V, Delpero JR Endoscopic ultrasound-guided drainage of pancreatic pseudocysts or pancreatic abscesses using a therapeutic echo endoscope. Endoscopy. 2001;33(6):473-477. 
8. Yusuf TE, Baron TH. Endoscopic transmural drainage of pancreatic pseudocysts: results of a national and an international survey of ASGE members. Gastrointest Endosc. 2006;63(2):223-237.

9. Varadarajulu S, Wilcox CM, Tamhane A, Eloubeidi MA, Blakely J, Canon CL. Role of EUS in drainage of peripancreatic fluid collections not amenable for endoscopic transmural drainage. Gastrointest Endosc. 2007;66(6):1107-1119.

10. Seifert H, Faust D, Schmitt T, Dietrich C, Caspary W, Wehrmann T. Transmural drainage of cystic peripancreatic lesions with a new largechannel echo endoscope. Endoscopy. 2001;33(12):1022-1026.

11. Antillon MR, Shah RJ, Stiegmann G, Chen YK. Single-step EUS-guided transmural drainage of simple and complicated pancreatic pseudocysts. Gastrointest Endosc. 2006;63(6):797-803.

12. Vosoghi M, Sial S, Garrett B, et al. EUS-guided pancreatic pseudocyst drainage: review and experience at Harbor-UCLA Medical Center. MedGenMed. 2002;4(3):2.
13. Kahaleh M, Shami VM, Conaway MR, et al. Endoscopic ultrasound drainage of pancreatic pseudocyst: a prospective comparison with conventional endoscopic drainage. Endoscopy. 2006;38(4):355-359.

14. Baron TH, Wiersema MJ. EUS-guided transesophageal pancreatic pseudocyst drainage. Gastrointest Endosc. 2000;52(4):545-549.

15. Azar RR, Oh YS, Janec EM, Early DS, Jonnalagadda SS, EdmundowiczSA. Wire-guided pancreatic pseudocyst drainage by using a modified needle knife and therapeutic echoendoscope. Gastrointest Endosc. 2006;63(4):688-692.

16. Ahlawat SK, Charabaty-Pishvaian A, Jackson PG, Haddad NG. Singlestep EUS-guided pancreatic pseudocyst drainage using a large channel linear array echoendoscope and cystotome: results in 11 patients. JOP. 2006;7(6):616-624

\section{Publish your work in this journal}

Therapeutics and Clinical Risk Management is an international, peerreviewed journal of clinical therapeutics and risk management, focusing on concise rapid reporting of clinical studies in all therapeutic areas, outcomes, safety, and programs for the effective, safe, and sustained use of medicines. This journal is indexed on PubMed Central, CAS,
EMBase, Scopus and the Elsevier Bibliographic databases. The manuscript management system is completely online and includes a very quick and fair peer-review system, which is all easy to use. Visit http://www.dovepress.com/testimonials.php to read real quotes from published authors.

Submit your manuscript here: http://www.dovepress.com/therapeutics-and-clinical-risk-management-journal 